with these Principles, to have in place management practices to effect such improvement, to measure their progress, and to report this progress as appropriate both internally and externally.

\section{Principles}

1. Corporate Priority:- To recognize environmental management as among the highest corporate priorities and as a key determinant to sustainable development; to establish policies, programmes, and practices, for conducting operations in an environmentally sound manner.

2. Integrated management:- To integrate these policies, programmes, and practices, fully into each business as an essential element of management in all its functions.

3. Process of improvement:- To continue to improve corporate policies, programmes, and environmental performance, taking into account technical developments, scientific understanding, consumer needs, and community expectations, with legal regulations as a starting-point; and to apply the same environmental criteria internationally.

4. Employee education:- To educate, train, and motivate, employees to conduct their activities in an environmentally responsible manner.

5. Prior assessment:- To assess environmental impacts before starting a new activity or project, and before decommissioning a facility or leaving a site.

6. Products and services:- To develop and provide products or services that have no undue environmental impact and are safe in their intended use, that are efficient in their consumption of energy and natural resources, and that can be recycled, reused, or disposed of safely.

7. Customer advice:- To advise, and where relevant educate, customers, distributors, and the public, in the safe use, transportation, storage, and disposal, of products provided; and to apply similar considerations to the provision of services.

8. Facilities and operations:- To develop, design, and operate, facilities, and conduct activities, taking into consideration the efficient use of energy and materials, the sustainable use of renewable resources, the minimization of adverse environmental impact and waste generation, and the safe and responsible disposal of residual wastes.

9. Research:- To conduct or support research on the environmental impacts of raw materials, products, processes, emissions, and wastes, associated with the enterprise, and on the means of minimizing any adverse impacts.

10. Precautionary approach:- To modify the manufacture, marketing, or use, of products or services or the conduct of activities, consistent with scientific and technical understanding, to prevent serious or irreversible environmental degradation.
11. Contractors and suppliers:- To promote the adoption of these principles by contractors acting on behalf of the enterprise, encouraging and, where appropriate, requiring improvements in their practices to make them consistent with those of the enterprise; and to encourage the widest possible adoption of these principles by suppliers.

12. Emergency preparedness:- To develop and maintain, where significant hazards exist, emergency preparedness plans in conjunction with the emergency services, relevant authorities, and the local community, recognizing potential transboundary impacts.

13. Transfer of technology:- To contribute to the transfer of environmentally sound technology and management methods throughout the industrial and public sectors.

14. Contributing to the common effort:- To contribute to the development of public policy and to business, governmental, and intergovernmental programmes and educational initiatives that will enhance environmental awareness and protection.

15. Openness to concerns:- To foster openness and dialogue with employees and the public, anticipating and responding to their concerns about the potential hazards and impacts of operations, products, wastes, or services, including those of transboundary or global significance.

16. Compliance and reporting:- To measure environmental performance; to conduct regular environmental audits and assessments of compliance with company requirements, legal requirements, and these principles; and periodically to provide appropriate information to the Board of Directors, shareholders, employees, the authorities, and the public.

\section{Support for the Charter}

The ICC is undertaking an extensive campaign to encourage member companies and others to express their support for the Charter. It has also invited certain international organizations to provide supportive messages.

A list of these companies, and the messages received from international organizations, are given in separate leaflets which are normally circulated together with the Charter. They may also be obtained from ICC Headquarters or ICC National Committees in nearly 60 countries.

INTERNATIONAL CHAMBER OF COMMERCE
38 Cours Albert ler
75008 Paris
France.
Tel: (33) (1) 49-53-28-28
Fax: (33) (1) 42-25-86-63
Telex: $650770 \mathrm{~F}$

\title{
International Chamber of Commerce (ICC) Code on Environmental Advertising
}

\section{Introduction}

The ICC International Code of Advertising Practice is widely accepted as the basis for promoting high standards of ethics in advertising, by self-regulation against a background of national and international law. The Code recognizes social responsibilities towards the consumer and the community, and is designed primarily as an instrument for self-discipline.
Because of the growing importance of environmental issues and the complexity of judging and verifying environmental claims, the ICC has decided to produce an Environmental Advertising Code, in order to extend the area of self-discipline and to help business to make responsible use of environmental advertising. National rules and guidelines, where applicable, have been taken into account, as well as the ICC's Business Charter for Sustainable Development, together with the ICC position paper on Environmental Labelling Schemes. 
Definitions in environmental terminology have not crystallized yet and vary currently between countries and between industrial sectors. Consequently, specific definitions are not included in the Code, but further work within the ICC may make it possible to recommend such definitions in a future edition which should then be incorporated into the International Code of Advertising Practice.

\section{Scope of the Code}

This Code applies to all advertisements containing environmental claims, in all media. It thus cover any form of advertising in which explicit or implicit reference is made to environmental or ecological aspects relating to the production, packaging, distribution, use/consumption, or disposal, of goods, services, or facilities (collectively termed products). All are covered by the Code.

This Code should be seen as an extension of the ICC Code of Advertising Practice, which therefore remains applicable on any aspect not specifically dealt with in this Code. The Code on Environmental Advertising should also be read in conjunction with the other ICC Codes of Marketing Practice, namely

- Marketing Research Practice

- Sales Promotion Practice

- Direct Marketing Practice

- Direct Sales Practice.

\section{Interpretation} letter.

This Code is to be applied in the spirit as well as in the

\section{Basic Principles}

All environmental advertising should be legal, decent, honest, and fully truthful. It should be consistent with environmental regulations and mandatory programmes, and should conform to the principles of fair competition, as generally accepted in business.

No advertisements or claims should be such as to impair public confidence in the efforts made by the business community to improve its ecological performance.

\section{Rules of Honesty}

Advertisements should be so framed as not to abuse consumers' concern for the environment, or exploit their possible lack of environmental knowledge.

\section{Environmental Behaviour}

Advertisements should not appear to approve or encourage actions which contravene the law, self-regulating codes, or generally-accepted standards of environmentally responsible behaviour.

\section{Truthful Presentation}

Advertisements [must never] contain any statement or presentation that is likely to mislead consumers in any way about the environmental aspects or advantages of products, or about the actions that are being taken by the advertiser in favour of the environment. Corporate advertisements can refer to specific products or actions, but not imply without justification that they extend to the whole performance of a company, group, or industry. Expressions such as 'environmentally friendly' or 'ecologically safe', implying that a product or activity has no impact - or only a positive impact - on the environment, should not be used unless a very high standard of proof is available.

\section{Scientific Research}

Advertisements should only use technical demonstrations or scientific findings about environmental impact when backed by serious scientific work.

Environmental jargon or scientific terminology is acceptable provided it is relevant and used in a way that can be readily understood by consumers.

\section{Testimonials and Endorsements}

In view of the rapid developments in environmental science and technology, particular care should be taken to ensure that, when testimonials or endorsements are used to support an environmental claim in an advertisement, changes in product formulation or market circumstances have not made the testimonial out-of-date.

\section{Superiority Over Competitors}

Environmental superiority over competitors can only be claimed when a significant advantage can be demonstrated. Claims in relation to competitive products, when based on the absence of a harmful ingredient or a damaging effect, are only acceptable when other products in the category do actually include the ingredient or cause the effect.

\section{Product Ingredients and Elements}

Environmental claims should not imply that they relate to more stages of a product's life-cycle, or to more properties of a product, than is justified, and should where necessary clearly indicate to which stage or which property they refer.

When advertisements refer to the reduction of ingredients or elements having a negative environmental impact, it must be clear what has been reduced. Alternative elements, if any, must bring a significant ecological improvement.

\section{Signs and Symbols}

Environmental signs or symbols should only be used in an advertisement when the source of these signs or symbols is clearly indicated, and there is no confusion over the meaning. Such signs and symbols should not falsely suggest official approval.

\section{Waste Collection Recycling and Disposal}

Environmental claims referring to waste separation, collection, processing, or disposal, are acceptable provided that the recommended method of collection, processing, or disposal, is generally accepted or sufficiently available, or the extent of availability is accurately described.

\section{Substantiation of Claims, etc.}

Descriptions, claims, or illustrations, relating to verifiable facts, should be capable of substantiation. Advertisers should have such substantiation available, so that they can produce evidence without delay to the selfregulatory bodies responsible for the operation of the International Code of Advertising Practice.

INTERNATIONAL CHAMBER OF COMMERCE 38 Cours Albert ler

75008 Paris

France. 